\title{
Circuit
}

Musiques contemporaines

\section{Katia Makdissi-Warren : étapes et oeuvres marquantes}

\section{Noémie Pascal}

Volume 29, numéro 3, 2019

URI : https://id.erudit.org/iderudit/1066488ar

DOI : https://doi.org/10.7202/1066488ar

Aller au sommaire du numéro

\section{Éditeur(s)}

Circuit, musiques contemporaines

ISSN

1183-1693 (imprimé)

1488-9692 (numérique)

Découvrir la revue

Citer ce document

Pascal, N. (2019). Katia Makdissi-Warren : étapes et oeuvres marquantes. Circuit, 29(3), 92-94. https://doi.org/10.7202/1066488ar d'utilisation que vous pouvez consulter en ligne.

https://apropos.erudit.org/fr/usagers/politique-dutilisation/ 


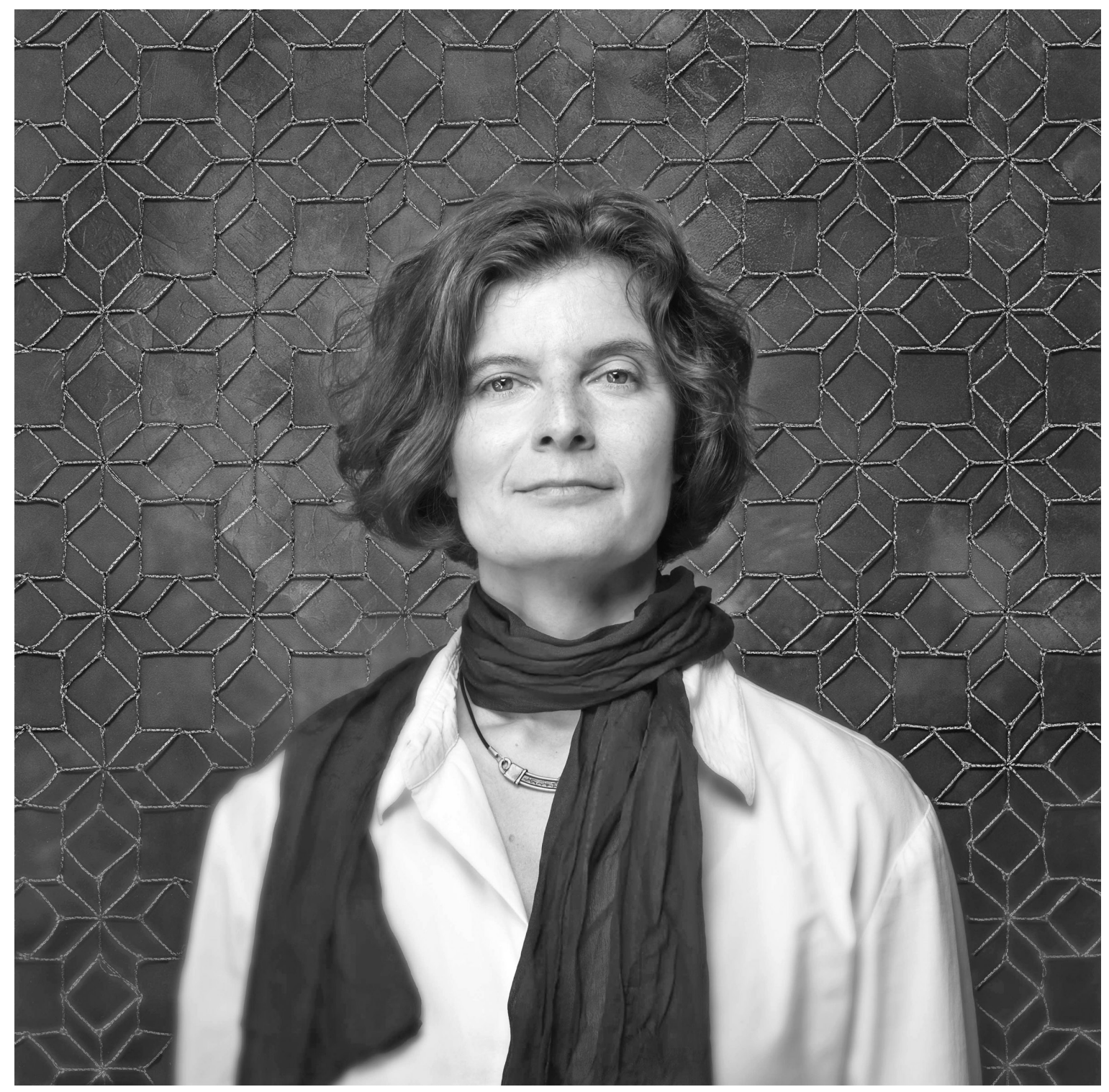

Katia Makdissi-Warren, 2019, par Jérôme Bertrand et Geneviève Bigué pour la Série hommage sMCQ. 


\section{ACT UALITÉS}

\section{SÉRIE HOMMAGE 2019-2020：KATIA MAKDISSI-WARREN Étapes et œuvres marquantes}

Noémie Pascal, smcQ

1959

- Arrivée au Québec de Hened Makdissi (Liban), grand-mère maternelle de Katia Makdissi-Warren 1970

- 23 juin, naissance à Sainte-Foy (Québec)

1977

- Début de l'apprentissage du piano (Ursulines, Québec)

1980

- La danse des amérindiens, pour piano (1 ${ }^{\text {ère }}$ composition)

1984-1987

- Dirige un chœur et un orchestre amateur 1985

- Découverte du chant de gorge inuit

- Découverte de la musique contemporaine (avec Gisèle Ricard, Université Laval)

1987-1990

- Études au Cégep de Sainte-Foy, en musique (piano) et sciences

1990-1995

- Études de composition au Conservatoire de musique de Québec
1995-1996

- Allemagne. Études de composition avec Manfred Stahnke

1997-1999

- France et Liban. Études arabes avec le Père Louis Hage

2000

- Retour à Québec

- Début de collaboration avec le Festival du monde arabe

2001

- Fondation de l'ensemble Zeugma

- Premier concert de Zeugma à Montréal (Maison de la culture Ahuntsic)

2003

- Samầi zirkouli (Orchestre national oriental de Beyrouth)

- Dialogue du silence (Geneviève Savoie, flûtiste)

2004

- Installation à Montréal

- Razzia et Algorythme (Festival du Monde Arabe)

2004-2007

- Doctorat en composition avec Michel Longtin (Université de Montréal) 
2006

- L’ensemble Zeugma devient Oktoécho

2007

- Carte Blanche (Arraymusic, Toronto)

- Premières inspirations jazz

2009

- $1^{\text {er }}$ album de Oktoécho, Éponyme

2010

- Début de la résidence de Oktoécho à la Maison de la culture Ahuntsic

- Compositions pour la plus haute tour du monde (Burj Khalifa, Dubaï)

2011

- Premières collaborations avec artistes autochtones

- Rave du Soleil (rencontre musique arabe et autochtone)

- Mouvances arabo-klezmer (rencontre christianisme, islam, judaïsme)

2012

- Début de collaboration avec Présence autochtone
2013

- Saimaniq (pour deux chanteuses de gorge inuites et ensemble)

- Fonte des glaciers (Ensemble contemporain de Montréal)

2014-2015

- Direction artistique du Festival Sefarad de Montréal

2015

- Trancestral (Présence autochtone)

2016

- Parade (Orchestre symphonique de Vancouver)

- Double Concerto (I Musici)

2017

- Collaboration avec Les Violons du Roy

2018

- Saimaniq, Prix Opus «Album de l'année Musiques du monde et musique traditionnelle québécoise »

2019

- La SMCQ lui consacre la $7^{\mathrm{e}}$ édition de sa Série hommage. 18 nouvelles œuvres. 